\title{
Work Outcomes Among Patients with Light Chain (AL) Amyloidosis: Findings from Three Patient Cohorts
}

\author{
Avery A Rizio (D)' \\ Kristen L McCausland (ID) \\ Michelle K White (D) \\ Tiffany P Quock $\mathbb{D}^{2}$ \\ 'QualityMetric Incorporated, LLC, \\ Johnston, RI, USA; ${ }^{2}$ Prothena Biosciences \\ Inc, South San Francisco, CA, USA
}

Background: Light chain (AL) amyloidosis is a rare and progressive disease that affects myriad organs and systems. Patients with cardiac involvement have the highest risk of death. This report compiles findings across three cohorts of patients with AL amyloidosis to understand patterns of employment and work impacts.

Methods: Data came from three cohorts recruited through patient advocacy organizations in the US. Patients in Cohort 1 completed the SF-36v2 ${ }^{\circledR}$ Health Survey (SF-36v2), the Work Productivity and Activity Impairments - Specific Health Problem (WPAI) questionnaire, and the 12-item Kansas City Cardiomyopathy Questionnaire (KCCQ-12). The relationship between work impacts (WPAI scores) and HRQoL (SF-36v2 scores) was investigated using multivariable logistic regression and summarized according to cardiac severity using New York Heart Association (NYHA) classes estimated from KCCQ-12 scores. Changes in employment, days of missed work, and long-term disability due to AL amyloidosis were summarized for patients diagnosed in the past 24 months and stratified by NYHA class (Cohort 2). Findings were contextualized using patient interviews (Cohort 3).

Results: Work-related impacts, especially reduced productivity, were common among patients with AL amyloidosis. WPAI scores were significantly related to HRQoL ( $<<0.05$ for all models). Among patients with cardiac involvement, the greatest degree of work impacts was observed for those in NYHA class 3 or 4. Changes in employment, missed work, and long-term disability were common among newly diagnosed patients, especially among those in NYHA class 3 or 4 Patient interviews supported the survey findings; patients described absences, reduced productivity at work, and loss of employment due to the disease and its treatment.

Conclusion: Patients with AL amyloidosis, particularly those with more advanced disease, experience impacts across a range of employment-related outcomes. These findings highlight the need for more effective treatments and interventions which may improve functioning and patient outcomes, while reducing indirect costs associated with the disease.

Keywords: AL amyloidosis, patient-reported outcomes, employment, work outcomes

\section{Introduction}

Light chain (AL) amyloidosis is a rare, progressive, and typically fatal disease caused by the extracellular deposition of misfolded immunoglobulin light chains. Soluble toxic aggregates and deposited fibrils (amyloid) can lead to progressive failure of organs (eg, the heart, kidneys, and nervous system), causing significant morbidity and mortality. While cardiac and renal involvement are the most prevalent clinical manifestations, cardiac involvement is associated with particularly poor survival. ${ }^{1-3}$ Symptoms of AL amyloidosis depend on organ involvement and may include fatigue, shortness of breath,
Correspondence: Avery A Rizio

QualityMetric Incorporated, LLC, I301

Atwood Avenue, Suite 216E, Johnston, RI, 02919, USA

$\mathrm{Tel}+\mid$ 40I-903-463।

Email arizio@qualitymetric.com 
weakness, edema, pain, dizziness, neuropathy, diarrhea, and constipation. ${ }^{4,5}$ Disease-related impacts have been observed across many domains of health-related quality of life (HRQoL) including aspects of both physical and mental wellbeing. ${ }^{6}$

While past studies have described how AL amyloidosis, and its associated treatments, impact patients' HRQoL, there is a scarcity of research evaluating other relevant outcomes, such as the ability to work. A conceptual model for AL amyloidosis includes "work limitations" as an area of impact; patient interviews conducted to develop the model indicated that patients were compelled to reduce work hours or stop working altogether due to disease-related symptoms. ${ }^{4}$ Such impacts have been reported in other similar or related diseases. For example, patients with hereditary transthyretin amyloidosis have qualitatively described work-related impacts such as missed work, reduced productivity while at work, and the need to retire early. ${ }^{7}$ Research among a sample of patients with multiple myeloma, a plasma cell disease, showed that while $66 \%$ of patients sampled were employed at the time of diagnosis, only $33 \%$ were employed at the time of the survey, despite many being well below the age of retirement. Participants also reported receiving disability income due to inability to perform their job. ${ }^{8}$ These results all point to the need for additional systematic evaluation of work-related impacts associated with $\mathrm{AL}$ amyloidosis.

Ability to work can be an important indicator of an individual's functional and financial independence and may play a role in psychosocial well-being; job loss can lead to increased feelings of stress, anxiety, and depressive symptoms. ${ }^{9}$ A better understanding of how $\mathrm{AL}$ amyloidosis impacts work-related outcomes can inform healthcare policies and treatments that reduce the burden of illness at the individual, family, and societal levels. This short report compiles findings across three cohorts of patients with AL amyloidosis to describe 1) the prevalence of work impacts; 2) the association between work impacts and HRQoL; 3) employment and work impacts among patients with cardiac involvement; and 4) patterns of employment and missed work among recently diagnosed patients. Data are supplemented with quotations from patient interviews for additional context.

\section{Methods}

\section{Participants and Procedure}

Analyses relied on data from three studies of patients with AL amyloidosis. Patients in Cohort 1 (NCT02574676; $\mathrm{N}=341$ ) completed an online survey in 2015 that included the SF-36v2 ${ }^{\circledR}$ Health Survey (SF-36v2; standard recall), a generic measure of $\mathrm{HRQoL}^{10}$; the short version of the Kansas City Cardiomyopathy Questionnaire (KCCQ-12), a congestive heart failure-specific measure of $\mathrm{HRQoL}^{11}$; and the Work Productivity and Activity Impairment Questionnaire - Specific Health Problem (WPAI), a measure of work impacts. ${ }^{12}$ Cohort $2(\mathrm{~N}=84)$ was comprised of recently diagnosed patients (ie, within 24 months of enrollment) who completed an online survey in 2017 that included several PROs and individual survey items about employment status. Cohort $3(\mathrm{~N}=10)$ included patients who participated in one-on-one concept elicitation interviews about their disease and treatment experience. All participants were recruited through US-based patient advocacy groups (though 48 of the 341 participants in Cohort 1 did not reside in the US). Data collection methods for Cohorts 1 and 3 have been described previously. ${ }^{6,13}$ Prior to data collection, each study was approved by the New England Independent Review Board (see Ethics Approval and Informed Consent section for more information).

\section{Statistical Analysis}

Work Impacts and Associations with HRQoL

Cross-sectional analyses among employed patients from Cohort $1(\mathrm{~N}=115)$ were conducted to examine the relationship between work impacts (measured by the WPAI) and HRQoL (measured by the SF-36v2). The WPAI was scored according to developer guidelines, producing three scores for employed patients based on a 7-day recall. Absenteeism reflects the amount of work time missed due to the disease; presenteeism reflects impairment at work or reduced effectiveness due to the disease. Work productivity loss is a composite of absenteeism and presenteeism scores. All 3 scores are expressed as percentages ranging from 0 to 100 , with higher scores indicating worse outcomes (eg, more missed work, less productivity). To quantify HRQoL, SF-36v2 component summary scores (physical component summary [PCS] and mental component summary [MCS]) were scored according to developer guidelines. PCS and MCS are scored relative to a general population mean of 50 and standard deviation (SD) of 10 .

To examine the prevalence of work-related impacts, employed patients were classified into one of 2 groups: those who reported any amount of absenteeism, presenteeism, or work productivity loss (ie, WPAI score $>0 \%$ ), and those who reported no impact (ie, WPAI score $=0 \%$ ). 
Cross-sectional associations between PCS and MCS scores and the three dichotomized WPAI scores were analysed using individual multivariable logistic models for each WPAI score, controlling for time since last treatment. Odds ratios were interpreted using 5 -point deficits in PCS and MCS scores, as 5 points represent $1 / 2$ SD of the general population mean score.

\section{Employment and Work Impacts Among Patients with Cardiac Involvement}

Cross-sectional analyses were also conducted using a sample of patients $(\mathrm{N}=137)$ from Cohort 1 who met the following criteria: 1) reported cardiac involvement, 2) provided information on their current employment status, and 3) completed the KCCQ-12 assessment.

The KCCQ-12 was scored according to developer guidelines; the overall score was used to estimate New York Heart Association Functional Classification (NYHA class) based on previously reported benchmarks. ${ }^{14}$ Patients with AL amyloidosis were grouped so that their average KCCQ-12 overall score matched the previously reported scores, \pm 7 points. NYHA class provides information on the severity of patients' heart failure symptoms, with class 4 representing the most severe symptoms; however, due to small sample sizes, classes 3 and 4 were combined for subsequent analyses. The percentage of patients in each estimated NYHA class was evaluated among those who were and were not employed. Among employed patients, average WPAI scores (absenteeism, presenteeism, work productivity loss) were calculated as a function of NYHA class.

\section{Employment and Missed Work Among Recently Diagnosed Patients}

Responses to three survey items on change in employment, receipt of long-term disability, and missed workdays over a 6-month period were summarized using data from Cohort $2(\mathrm{~N}=84)$. Item responses were stratified according to the estimated NYHA class for patients with cardiac involvement, with stratification following a similar method described earlier, such that KCCQ-12 overall score matched previously reported scores, \pm 8 points. Due to small sample sizes, classes 1 and 2 were combined.

\section{Qualitative Descriptors of Work Impacts}

Transcripts from patient interviews were reviewed and content coded using a grounded theory approach to identify emerging themes. ${ }^{15}$ Given the goal of this report, select quotations related to patient descriptors of employment and work impacts are reported.

\section{Results}

\section{Patient Demographics and Clinical}

\section{Characteristics}

Select demographic and clinical characteristics for Cohort 1 are presented in Table 1. Patients in Cohorts 2 and 3 were similar in age to Cohort 1 (Cohort 2: mean age $=57.8$ years; Cohort 3 : mean age $=57.2$ years). Like Cohort 1 , more than half of the patients in Cohorts 2 and 3 reported cardiac involvement (Cohort 2=55\%; Cohort $3=60 \%$ ).

\section{Work Impacts and Associations with HRQoL}

As depicted in Figure 1, employed patients primarily experienced AL amyloidosis-related work impacts over

Table I Demographic and Clinical Characteristics of Participants Enrolled in Cohort I

\begin{tabular}{|c|c|c|c|}
\hline & \multirow{2}{*}{$\begin{array}{c}\text { Total Patient } \\
\text { Sample } \\
(\mathbf{N}=\mathbf{3 4} \text { I) }\end{array}$} & \multicolumn{2}{|c|}{ Employment Status ${ }^{\mathrm{a}}$} \\
\hline & & $\begin{array}{l}\text { Employed } \\
(N=\mid 15)\end{array}$ & $\begin{array}{c}\text { Not } \\
\text { Employed } \\
(\mathrm{N}=185)\end{array}$ \\
\hline & Mean (SD) & Mean (SD) & $\begin{array}{l}\text { Mean } \\
\text { (SD) }\end{array}$ \\
\hline Age (years) & $60.5(10.2)$ & $56.1(9.3)$ & $62.4(10.3)$ \\
\hline \multirow{2}{*}{$\begin{array}{l}\text { Time since diagnosis } \\
\text { (years) }\end{array}$} & $4.5(4.0)$ & $4.5(3.9)$ & $4.3(4.1)$ \\
\hline & $\mathbf{N}(\%)$ & $\mathbf{N}(\%)$ & $\mathbf{N}(\%)$ \\
\hline \multicolumn{4}{|l|}{ Gender $^{b}$} \\
\hline Male & $160(47.06)$ & $50(43.86)$ & $93(50.27)$ \\
\hline Female & $180(52.94)$ & $64(56.14)$ & $92(49.73)$ \\
\hline \multicolumn{4}{|l|}{$\begin{array}{l}\text { Number of organs } \\
\text { involved }\end{array}$} \\
\hline One & $95(27.86)$ & $32(27.83)$ & $54(29.19)$ \\
\hline Two & $89(26.10)$ & $35(30.43)$ & $41(22.16)$ \\
\hline Three or more & $157(46.04)$ & $48(41.74)$ & $90(48.65)$ \\
\hline \multicolumn{4}{|l|}{$\begin{array}{l}\text { Organ/System } \\
\text { Involvement }^{c}\end{array}$} \\
\hline Heart & $178(52.20)$ & $51(44.35)$ & $103(55.68)$ \\
\hline Kidney & $214(62.76)$ & $75(65.22)$ & $112(60.54)$ \\
\hline Liver & $49(14.37)$ & $20(17.39)$ & $23(12.43)$ \\
\hline Nerves & $126(36.95)$ & 37 (32.17) & $70(37.84)$ \\
\hline Gastrointestinal & I $48(43.40)$ & $49(42.61)$ & $84(45.4 I)$ \\
\hline Other & 117 (34.3I) & $36(31.30)$ & $64(34.59)$ \\
\hline
\end{tabular}

Notes: ${ }^{a}$ Forty-one participants did not report on their employment status and so are only included in the "total patient sample" column. 'One participant did not provide a response to this item; percentages are based on available data. "Multiple response options allowed; frequency sums to $>100 \%$.

Abbreviation: SD, standard deviation. 


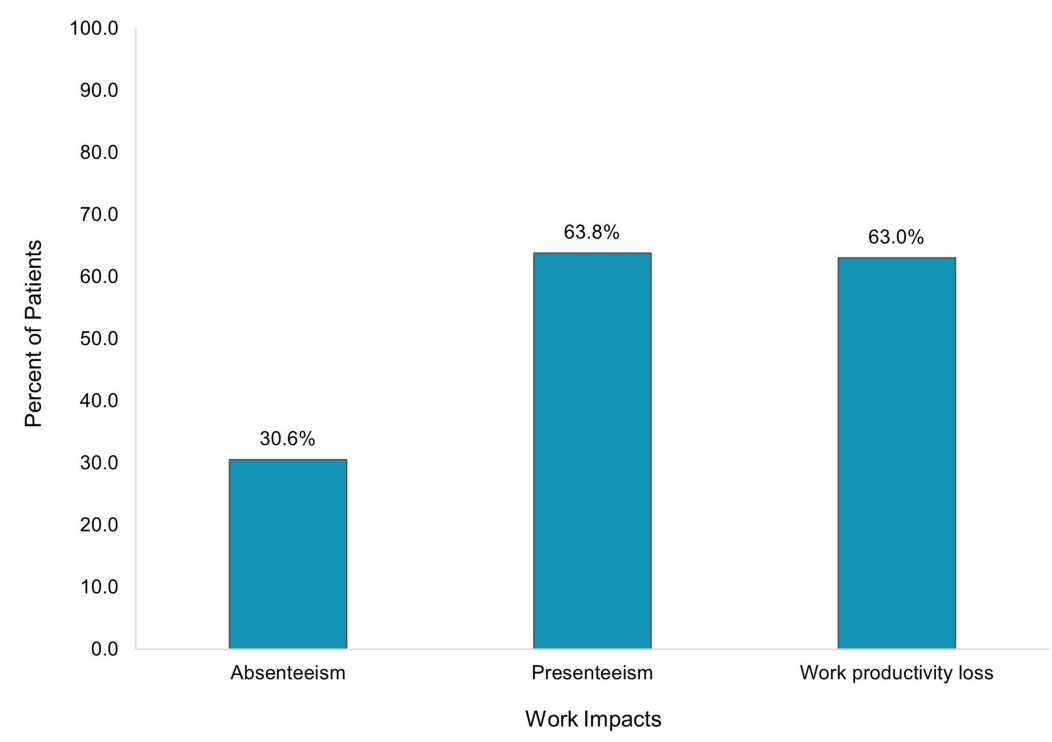

Figure I Work impacts among employed patients with AL amyloidosis.

Notes: Figure depicts the percent of employed patients who experienced a work impact (WPAl score $>0 \%$ ) over the past 7 days.

the past 7 days in the form of presenteeism (ie, reduced productivity at work; $63.8 \%$ of patients), which also contributed to an overall loss in work productivity (63.0\% of patients). A smaller percentage of patients reported work impacts in the form of absenteeism (ie, missed work; $30.6 \%$ of patients) over the past 7 days.

Physical well-being (as measured by PCS of the SF36v2) was significantly associated with all 3 work impacts assessed by the WPAI $(\mathrm{p}<0.05$ for all associations; Table 2). Each 5-point deficit in PCS was associated with 80-90\% greater odds of experiencing absenteeism, presenteeism, or work productivity loss. For example, a 5-point deficit in PCS was associated with $90 \%$ greater odds of missing work (absenteeism) due to AL amyloidosis over a 7-day period. Likewise, a 5-point deficit in PCS was associated with $80 \%$ greater odds of experiencing reduced productivity while at work (presenteeism) due to $\mathrm{AL}$ amyloidosis.

Mental well-being (as measured by MCS of the SF36v2) was also significantly associated with all three work impacts assessed by the WPAI $(\mathrm{p}<0.05$ for all associations; Table 2). A 5-point deficit in MCS was associated with $28 \%$ greater odds of missing work due to $\mathrm{AL}$ amyloidosis. Deficits in MCS were associated with even greater odds of presenteeism and work productivity loss, as each 5-point deficit in MCS more than doubled the odds of experiencing presenteeism or work productivity loss (2.19 and 2.16 greater odds, respectively).

\section{Employment and Work Impacts Among Patients with Cardiac Involvement}

Table 3 depicts the percentage of employed and non-employed patients with cardiac involvement from Cohort 1 , stratified by estimated NYHA class. Only $13.3 \%$ of the employed patients with cardiac involvement were in NYHA class 3 or 4 . However, $42.4 \%$ of the non-employed patients with cardiac involvement were in class 3 or 4 .

Among employed patients with cardiac involvement, the greatest work impacts were related to presenteeism and subsequent overall productivity loss (Figure 2). The greatest degree of work impacts was observed for those in NYHA class 3 or 4 . Average presenteeism and overall productivity loss scores for patients in NYHA class 3 or 4 were more than

Table 2 Association Between Health-Related Quality of Life and Work-Related Outcomes

\begin{tabular}{|l|c|c|c|}
\hline $\begin{array}{l}\text { Work-Related } \\
\text { Outcome }\end{array}$ & $\begin{array}{c}\text { Measure of } \\
\text { HRQoL }\end{array}$ & $\begin{array}{c}\text { 5-Point } \\
\text { Odds Ratio }\end{array}$ & $\mathbf{9 5 \% ~ C l}$ \\
\hline Absenteeism & PCS & 1.90 & $1.43-2.52$ \\
& MCS & 1.28 & $1.03-1.59$ \\
\hline Presenteeism & PCS & 1.80 & $1.35-2.40$ \\
& MCS & 2.19 & $1.53-3.14$ \\
\hline Work productivity & PCS & 1.85 & $1.37-2.49$ \\
loss & MCS & 2.16 & $1.50-3.11$ \\
\hline
\end{tabular}

Notes: All work-related outcomes are significantly associated with PCS and MCS, $\mathrm{p}<0.05$. Each model controlled for time since last treatment $(0,<1$ year, $\geq 1$ year). Abbreviations: $\mathrm{Cl}$, confidence interval; $\mathrm{HRQ} \mathrm{L}$, health-related quality of life; MCS, Mental component summary of the SF-36v2 Health Survey; PCS, Physical component summary of the SF-36v2 Health Survey. 
Table 3 Employment Status According to Cardiac Stage

\begin{tabular}{|l|c|c|}
\hline \multirow{2}{*}{$\begin{array}{l}\text { Estimated NYHA } \\
\text { Class }\end{array}$} & \multicolumn{2}{|c|}{ Employment Status (n, \%) } \\
\cline { 2 - 3 } & $\begin{array}{c}\text { Employed } \\
\mathbf{( N = 4 5 )}\end{array}$ & $\begin{array}{c}\text { Not Employed } \\
\mathbf{( N = 9 2 )}\end{array}$ \\
\hline Class I & $9(20.00)$ & $10(10.87)$ \\
Class 2 & $30(66.67)$ & $43(46.74)$ \\
Class 3-4 & $6(13.33)$ & $39(42.39)$ \\
\hline
\end{tabular}

Abbreviation: NYHA, New York Heart Association.

double the average score for those in class 2. For example, average presenteeism scores were 25.0 for those in NYHA class 2, and 58.0 for those in NYHA class 3-4 (on a scale of $0-100$, with higher scores indicating greater presenteeism/ work impacts). Average absenteeism scores for patients in NYHA class 3 or 4 were approximately 6 times greater than those for patients in class 2: those in NYHA class 2 had an average absenteeism score of 7.5, while those in NYHA class 3-4 had an average absenteeism score of 46.4 .

\section{Employment and Missed Work Among Recently Diagnosed Patients}

As shown in Table 4, nearly half of all recently diagnosed patients had experienced a change in their employment status (45.2\%), and nearly a quarter had been on longterm disability due to AL amyloidosis (23.8\%). Among recently diagnosed patients with cardiac involvement, higher prevalence of employment changes and long-term disability was observed among those in NYHA class 4: $60 \%$ of those in NYHA class 4 reported changed employment due to AL amyloidosis or its treatments, and 50\% had been on long-term disability.

Seventy-nine percent of employed patients reported missing at least 1 day of work over the past 6 months due to $\mathrm{AL}$ amyloidosis, with $41.7 \%$ missing more than 20 days (Table 5). Descriptively, employed patients with cardiac involvement who were classified as being in NYHA class 1-2 missed fewer days of work than those in NYHA class 3, while none of the class 4 patients were currently employed.

\section{Descriptions of Work Impacts for Patient Interviews}

As reported in White 2017, ${ }^{13} 7$ of the 10 patients described experiencing work-related impacts due to $\mathrm{AL}$ amyloidosis. The quotes depicted in Table 6, which have not been previously published, parallel the type and extent of impacts reflected in the results described earlier, highlighting experiences related to reduced productivity, absences, and loss of employment.

\section{Discussion}

While work impacts have been described by patients with AL amyloidosis in qualitative settings, ${ }^{4,13}$ to our knowledge, this is the first report to quantify these impacts using standardized assessments. Our data also provide insights into the types of work impacts experienced, the types of patients

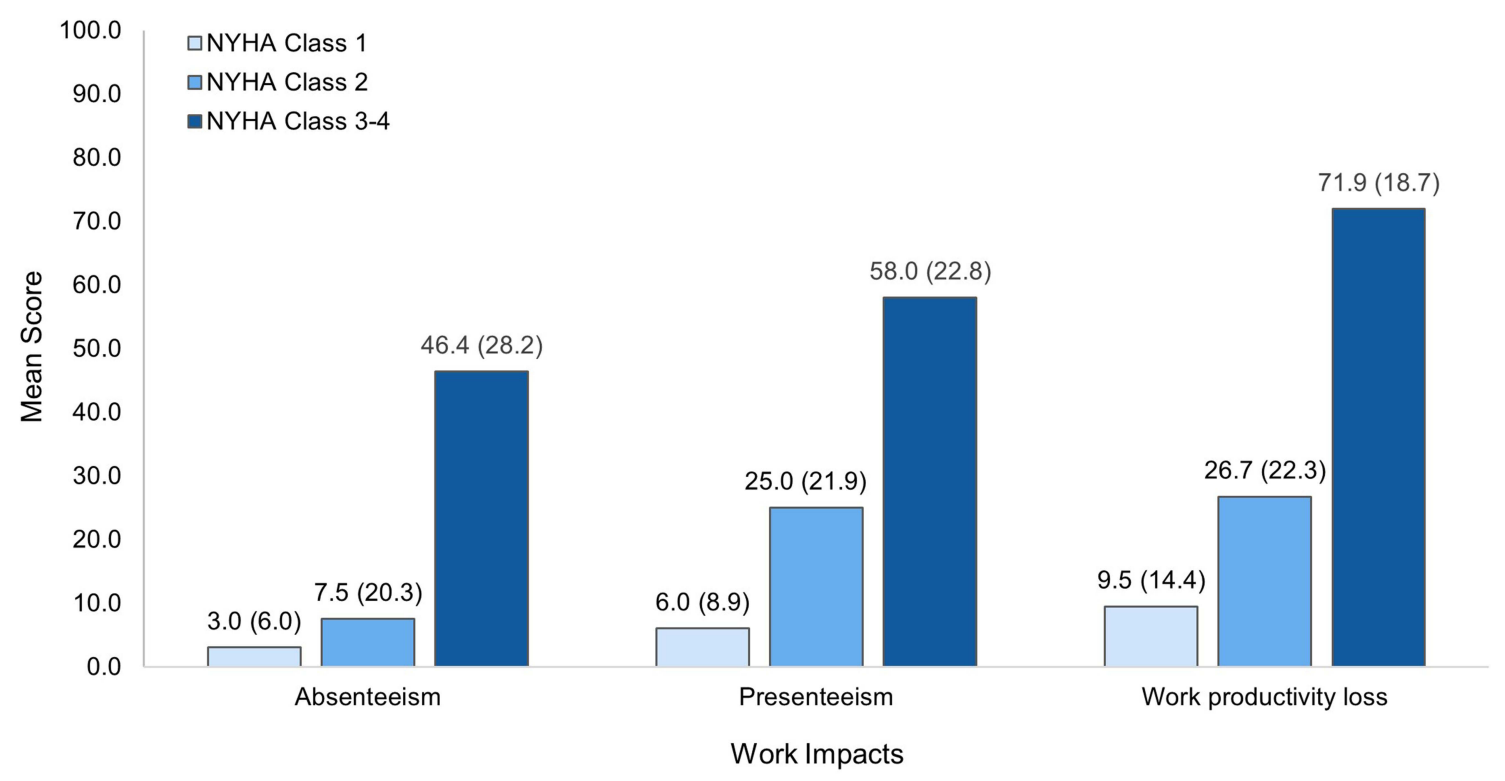

Figure 2 Work impacts according to cardiac stage among employed patients.

Note: Scores are presented as mean (standard deviation).

Abbreviation: NYHA, New York Heart Association. 
Table 4 Changes in Employment Status and Disability Due to AL Amyloidosis

\begin{tabular}{|l|c|c|c|c|}
\hline & All Patients & \multicolumn{2}{|c|}{ Patients with Cardiac Involvement (n=46) } \\
\cline { 3 - 5 } & $(\mathbf{N = 8 4 )}$ & $\begin{array}{c}\text { NYH Class I-2 } \\
(\mathbf{n = 1 3 )}\end{array}$ & $\begin{array}{c}\text { NYHA Class 3 } \\
(\mathbf{n}=\mathbf{2 3})\end{array}$ & $\begin{array}{c}\text { NYHA Class 4 } \\
(\mathbf{n}=1 \mathbf{0})\end{array}$ \\
\hline $\begin{array}{l}\text { Changed employment status due to AL amyloidosis or } \\
\text { treatment (n, \%) }\end{array}$ & $38(45.2)$ & $6(46.15)$ & $11(47.83)$ & $6(60.00)$ \\
\hline $\begin{array}{l}\text { Has been on long term disability due to AL amyloidosis } \\
(\mathrm{n}, \%)\end{array}$ & $20(23.8)$ & $11(7.69)$ & $10(43.48)$ & $5(50.00)$ \\
\hline
\end{tabular}

Abbreviation: NYHA, New York Heart Association.

Table 5 Days of Missed Work Due to AL Amyloidosis Over a 6-Month Period Among Recently Diagnosed Employed Patients

\begin{tabular}{|l|c|c|c|c|}
\hline & All Employed Patients (N=24) & \multicolumn{3}{|c|}{ Employed Patients with Cardiac Involvement (n=12) } \\
\cline { 2 - 5 } & & NYHA Class I-2 (n=6) & NYHA Class 3 (n=6) & NYHA Class 4 (n=0) \\
\hline 0 days & $5(20.83)$ & $2(33.33)$ & 0 & 0 \\
I-20 days & $9(37.50)$ & $3(50.00)$ & $4(66.67)$ & 0 \\
More than 20 days & $10(41.67)$ & $1(16.67)$ & $2(33.33)$ & 0 \\
\hline
\end{tabular}

Notes: Total sample sizes $(\mathrm{N}=24 ; 12)$ represent the number of patients who were employed in the last 6 months.

Abbreviation: NYHA, New York Heart Association.

Table 6 Patient Descriptors of Work Impacts Due to AL Amyloidosis

\begin{tabular}{|l|l|l|}
\hline Representative Patient Quote & Patient Characteristics & $\begin{array}{l}\text { Type of Employment } \\
\text { Impact Described }\end{array}$ \\
\hline $\begin{array}{l}\text { I never thought of myself as a Type A personality, everybody else would. So, my } \\
\text { whole career was my identity, it is who I am. It is all the time. So, I was not forced } \\
\text { into retirement by my agency, nobody kicked me out, it was clear that I could not } \\
\text { function because of my health. I was clear the job required more from me than } \\
\text { I could physically handle. That was devastating. }\end{array}$ & $\begin{array}{l}\text { Male, 62, cardiac, kidney, } \\
\text { nervous system involvement }\end{array}$ & $\begin{array}{l}\text { Reduced productivity; } \\
\text { loss of employment }\end{array}$ \\
\hline $\begin{array}{l}\text { I ultimately ended up moving home because my health was so bad. After I did that } \\
\text { they fired me, which was horrible. }\end{array}$ & Male, 63, cardiac involvement & Loss of employment \\
\hline $\begin{array}{l}\text { I started my chemotherapy on [date redacted], and I spent three months not } \\
\text { working because of the severity of the symptoms. }\end{array}$ & $\begin{array}{l}\text { Female, 49 cardiac } \\
\text { involvement }\end{array}$ & Absence from work \\
\hline $\begin{array}{l}\text { The fatigue, I try real hard to push it back, sometimes they get ... the symptoms get } \\
\text { real bad and I have found myself sitting at my desk and I sort of phase out. And then } \\
\text { all of the sudden I will be aware of oh good grief, did my boss just walk by? }\end{array}$ & $\begin{array}{l}\text { Female, 63, kidney } \\
\text { involvement }\end{array}$ & Reduced productivity \\
\hline
\end{tabular}

most likely affected, and the relationships between these impacts and patients' physical and mental well-being.

Among the full sample of Cohort 1 participants, approximately half were not employed at the time of the survey. Among those with cardiac involvement, approximately $67 \%$ were not employed; of those who were employed, very few were classified with NYHA class 3 or 4 cardiac involvement. While lack of employment could be driven by myriad factors, nearly half of recently diagnosed patients (Cohort 2) reported a change in their employment status due to AL amyloidosis. Collectively, these results strongly indicate that patients with AL amyloidosis, particularly those with advanced AL amyloidosis, have difficulty maintaining employment due to their disease and/or treatments - a finding also reflected in patient interviews.

This study illustrates not only the potential loss of employment faced by patients with AL amyloidosis, which may lead to other downstream poor clinical and HRQoL outcomes but also highlights impacts experienced by patients who are still employed. More than half of the participants in Cohort 1 experienced productivity loss (often driven by presenteeism) over a 7-day period due to their AL amyloidosis. Though absenteeism was less common, the proportion of patients 
who reported work absences over the 7-day period (30.6\%) exceeded that reported by patients with other chronic diseases, such as relapsing multiple sclerosis $(14 \%)^{16}$ and rheumatoid arthritis $(19 \%){ }^{17}$

Work-related impacts were particularly pronounced for those with more advanced disease (NYHA class 3 or 4). These patients reported greater absenteeism, presenteeism, and overall productivity loss than patients with ankylosing spondylitis ${ }^{18}$ chronic obstructive pulmonary disease, ${ }^{19}$ HER2-positive breast cancer (during metastatic breast cancer treatment), ${ }^{20}$ and dialysis-dependent chronic kidney disease. ${ }^{21}$ Comparing results to those obtained in other disease areas may allow researchers and clinicians to contextualize the experiences of patients with AL amyloidosis, particularly given the limited research in this area.

There are notable study limitations that must be acknowledged. The sample used in these analyses is likely not representative of the greater AL amyloidosis patient population. Participants were recruited from US-based advocacy groups, and as such, mainly reflect the experiences of US-based patients whose treatment and employment experiences may differ from those in other countries (though a small number of non-US patients participated). In addition, advocacy groups primarily distributed recruitment messaging via social media and other online channels - recruitment methods that often yield an over-representation of white participants with higher education, income, and employment opportunities. ${ }^{22,23}$ Individual decisions related to employment may reflect broader nation- and job/industry-specific differences in workrelated policies (eg, availability of sick leave, job-dependent health insurance). Patients at risk for the poorest outcomes those with cardiac involvement (and among that group, those with very advanced heart disease and at highest risk of early mortality) - are under-represented in the study sample. The sample includes many long-term survivors; patients with a more acute disease status may be less likely to participate in this type of study. As such, the composition of the participant sample may contribute to an underestimation of the impacts experienced by those with AL amyloidosis. Small sample sizes, especially when stratifying by NYHA class, may limit the interpretability of our findings. Due to small sample sizes, the functional classes had to be grouped, which limits the ability to understand the potentially unique impacts experienced by each individual group. NYHA class was approximated using KCCQ-12 scores and may have led to misclassification. Despite these limitations, these results are a valuable step in identifying impacts experienced by patients with AL amyloidosis.
While it is largely accepted that personal and societal costs of serious and life-threatening diseases can be substantial, the full socio-economic impact of rare diseases, particularly the indirect costs associated with lost work productivity and formal or informal care, often go unreported. ${ }^{24}$ This study highlighted notable work impacts - even in an older disease population - suggesting both societal impacts and an unmet need for effective treatments and supportive policies/interventions for patients with $\mathrm{AL}$ amyloidosis and their families. Future research, either qualitative or quantitative in nature, should evaluate employment experiences as a function of type of work; it is possible that work-related impacts depend at least partially on the type or nature of a patient's employment. While the analyses presented here included a focus on patients with cardiac involvement, exploring the work-related impacts experienced by patients with other types of organ involvement may contribute to a more complete understanding of the disease. Future research with larger samples - particularly larger samples of patients with more advanced disease - is needed to better evaluate longitudinal work outcomes and understand the full cost-of-illness of this debilitating disease in both newly diagnosed patients and long-term survivors.

\section{Abbreviations}

AL, amyloidosis: light chain amyloidosis; HRQoL, healthrelated quality of life; KCCQ-12, 12-item Kansas City Cardiomyopathy Questionnaire; MCS, mental component summary of the SF-36v2; NYHA, New York Heart Association; PCS, physical component summary of the SF36v2; SD, standard deviation; SF-36v2, SF-36v2 ${ }^{\circledR}$ Health Survey; WPAI, Work Productivity and Activity Impairments Questionnaire.

\section{Data Sharing Statement}

The data sets analyzed in the current study are available from the corresponding author on reasonable request.

\section{Ethics Approval and Informed Consent}

All procedures performed in studies involving human participants were in accordance with the ethical standards of the institutional and/or national research committee and with the 1964 Helsinki declaration and its later amendments or comparable ethical standards. The informed consent forms, protocols, surveys, and interview guide were approved by the New England Independent Review Board (Cohort 1: IRB \# 15355, Cohort 2: IRB \# 120170231, Cohort 3: IRB \# 15-140). 
The New England Independent Review Board is an independent review board, as opposed to a board that is affiliated with a specific hospital, university, or other institution. As this was not site-based research, approval from individual institutions' boards was not necessary. All participants provided consent.

\section{Acknowledgments}

We would like to thank the Amyloidosis Support Groups, Amyloidosis Foundation, and Amyloidosis Research Consortium for their help in patient outreach, and each of the patients who offered their time and insight for this project.

\section{Author Contributions}

All authors contributed to data analysis, drafting, or revising the article, have agreed on the journal to which the article will be submitted, gave final approval of the version to be published, and agree to be accountable for all aspects of the work.

\section{Funding}

This research was funded by Prothena Biosciences Ltd, Dublin, Ireland, a member of the Prothena Corporation plc group. The study sponsor was involved in research design, data interpretation, and drafting of the article.

\section{Disclosure}

TPQ is an employee and stockholder of Prothena Corporation plc. AAR, KLM, and MKW are employees of QualityMetric Incorporated, LLC, and received funding from Prothena Biosciences Ltd to conduct this research. The authors report no other conflicts of interest in this work.

\section{References}

1. Gertz MA. Immunoglobulin light chain amyloidosis: 2020 update on diagnosis, prognosis, and treatment. Am J Hematol. 2020;95 (7):848-860. doi:10.1002/ajh.25819

2. Milani P, Merlini G, Palladini G. Light chain amyloidosis. Mediterr $J$ Hematol Infect Dis. 2018;10(1):e2018022. doi:10.4084/ MJHID.2018.022

3. Merlini G, Dispenzieri A, Sanchorawala V, et al. Systemic immunoglobulin light chain amyloidosis. Nat Rev Dis Primers. 2018;4(1):38. doi:10.1038/s41572-018-0034-3

4. Lin HM, Seldin D, Hui A-M, Berg D, Dietrich CN, Flood E. The patient's perspective on the symptom and everyday life impact of $\mathrm{AL}$ amyloidosis. Amyloid. 2015;22(4):244-251. doi:10.3109/ 13506129.2015.1102131

5. McCausland KL, White MK, Guthrie SD, et al. Light chain (AL) amyloidosis: the journey to diagnosis. Patient. 2018;11(2):207-216. doi:10.1007/s40271-017-0273-5

6. Bayliss M, McCausland KL, Guthrie SD, White MK. The burden of amyloid light chain amyloidosis on health-related quality of life. Orphanet J Rare Dis. 2017;12(1):15. doi:10.1186/s13023-016-0564-2
7. Lovley A, Raymond K, Guthrie SD, Pollock M, Sanchorawala V, White MK. Patient-reported burden of hereditary transthyretin amyloidosis on functioning and well-being. $J$ Patient Rep Outcomes. 2021;5(1):3. doi:10.1186/s41687-020-00273-y

8. Goodwin JA, Coleman EA, Sullivan E, et al. Personal financial effects of multiple myeloma and its treatment. Cancer Nurs. 2013;36(4):301-308. doi:10.1097/NCC.0b013e3182693522

9. Brand JE. The far-reaching impact of job loss and unemployment. Annu Rev Sociol. 2015;41:359-375. doi:10.1146/annurev-soc-071913-043237

10. Maruish ME. User's Manual for the SF-36v2 Health Survey. 3rd ed. QualityMetric; 2011.

11. Spertus JA, Jones PG. Development and validation of a short version of the Kansas City cardiomyopathy questionnaire. Circ Cardiovasc Qual Outcomes. 2015;8(5):469-476. doi:10.1161/ CIRCOUTCOMES. 115.001958

12. Reilly MC, Zbrozek AS, Dukes EM. The validity and reproducibility of a work productivity and activity impairment instrument. Pharmacoeconomics. 1993;4(5):353-365. doi:10.2165/00019053199304050-00006

13. White MK, Bayliss MS, Guthrie SD, Raymond KP, Rizio AA, McCausland KL. Content validation of the SF-36v2 ${ }^{\circledR}$ health survey with AL amyloidosis patients. J Patient Rep Outcomes. 2017;1(1):13. doi:10.1186/s41687-017-0020-7

14. Green CP, Porter CB, Bresnahan DR, Spertus JA. Development and evaluation of the Kansas City cardiomyopathy questionnaire: a new health status measure for heart failure. $J$ Am Coll Cardiol. 2000;35 (5):1245-1255. doi:10.1016/s0735-1097(00)00531-3

15. Vollstedt M, Rezat S. An introduction to grounded theory with a special focus on axial coding and the coding paradigm. In: Kaiser G, Presmeg N, editors. Compendium for Early Career Researchers in Mathematics Education. Springer International Publishing; 2019:81-100.

16. Glanz BI, Dégano IR, Rintell DJ, Chitnis T, Weiner HL, Healy BC. Work productivity in relapsing multiple sclerosis: associations with disability, depression, fatigue, anxiety, cognition, and health-related quality of life. Value Health. 2012;15(8):1029-1035. doi:10.1016/j.jval.2012.07.010

17. Bansback N, Zhang W, Walsh D, et al. Factors associated with absenteeism, presenteeism and activity impairment in patients in the first years of RA. Rheumatology. 2012;51(2):375-384. doi:10.1093/ rheumatology/ker385

18. Boonen A, Boone C, Albert A, Mielants H. Understanding limitations in at-work productivity in patients with active ankylosing spondylitis: the role of work-related contextual factors. $J$ Rheumatol. 2015;42(1):93-100. doi:10.3899/jrheum.131287

19. Allen-Ramey FC, Gupta S, DiBonaventura MD. Patient characteristics, treatment patterns, and health outcomes among COPD phenotypes. Int J Chron Obstruct Pulmon Dis. 2012;7:779-787. doi:10.2147/COPD.S35501

20. Verrill M, Wardley AM, Retzler J, et al. Health-related quality of life and work productivity in UK patients with HER2-positive breast cancer: a cross-sectional study evaluating the relationships between disease and treatment stage. Health Qual Life Outcomes. 2020;18 (1):353. doi:10.1186/s12955-020-01603-w

21. van Haalen H, Jackson J, Spinowitz B, Milligan G, Moon R. Impact of chronic kidney disease and anemia on health-related quality of life and work productivity: analysis of multinational real-world data. BMC Nephrol. 2020;21(1):88. doi:10.1186/s12882-020-01746-4

22. Whitaker C, Stevelink S, Fear N. The use of Facebook in recruiting participants for health research purposes: a systematic review. $J$ Med Internet Res. 2017;19(8):e290. doi:10.2196/jmir.7071

23. Topolovec-Vranic J, Natarajan K. The use of social media in recruitment for medical research studies: a scoping review. J Med Internet Res. 2016;18(11):e286. doi:10.2196/jmir.5698

24. Angelis A, Tordrup D, Kanavos P. Socio-economic burden of rare diseases: a systematic review of cost of illness evidence. Health Policy. 2015;119(7):964-979. doi:10.1016/j.healthpol.2014.12.016 


\section{Publish your work in this journal}

Patient Related Outcome Measures is an international, peer-reviewed, open access journal focusing on treatment outcomes specifically relevant to patients. All aspects of patient care are addressed within the journal and practitioners from all disciplines are invited to submi their work as well as healthcare researchers and patient support groups.

Submit your manuscript here: http://www.dovepress.com/patient-related-outcome-measures-journal
The manuscript management system is completely online and includes a very quick and fair peer-review system. Visit http://www. dovepress.com/testimonials.php to read real quotes from published authors. 